REVIEW ARTICLE

\title{
The Nucleus Basalis of Meynert
}

\author{
Cheryl Ezrin-Waters and L. Resch
}

\begin{abstract}
The nucleus basalis of Meynert has been studied extensively in the recent literature. Interest in this nucleus has resulted from the discovery that it is a major source of cortical cholinergic input and that there is neuronal loss in the nucleus basalis in some dementing illnesses. Consistent and severe involvement of the nucleus basalis of Meynert has been found in Alzheimer's disease and in the dementia accompanying Parkinson's disease. Occasional involvement is present in other dementing illnesses, such as progressive supranuclear palsy, Parkinsonism-Dementia complex of Guam, dementia pugilistica, Pick's disease, Korsakoff's syndrome, Down's Syndrome and CreutzfeldtJakob disease. Huntington's disease spares this nucleus. However, the role of the nucleus in cognitive function is as yet undetermined. Even its alteration with normal aging remains controversial. This review details the pathological studies of this region to date, with particular emphasis on the dementias. Its role in the dementias of Alzheimer's disease and Parkinson's disease is specifically addressed.
\end{abstract}

RÉSUMÉ: Le noyau basal de Meynert - Une revue Le noyau basal de Meynert (nbM) a été intensément étudié dans la littérature récente. L'intérêt porté à ce noyau résulte du fait qu'il est l'origine principale des fibres cholinergiques à destination corticale et que c'est à ce niveau qu'il y a perte neuronale dans certaines maladies avec démence. Une atteinte constante et sévère de ce noyau a été trouvée dans la maladie d'Alzheimer et dans la démence accompagnant la maladie de Parkinson. On retrouve une atteinte occasionnelle dans plusieurs autres entités, comme le complexe Parkinson-démence du Guam, la démence pugilistique, la maladie de Pick, le syndrome de Korsakoff, le syndrome de Down et la maladie de Creutzfeldt-Jakob. Par contre le noyau est épargné dans la maladie de Huntington. On ne connaît pas encore le rôle exact de ce noyau dans les fonctions cognitives. Même les modifications inhérentes au vieillissement sont controversées. La présente revue insiste sur les modifications neuropathologiques de cette région, surtout dans les démences et, particulièrement, dans la démence accompagnant les maladies d'Alzheimer et de Parkinson.

Can. J. Neurol. Sci. 1986; 13:8-14

Theodor Meynert, a teacher of neuroanatomy, neuropathology and psychiatry, believed that neuropsychiatric disease could be understood on the basis of structural changes in the brain.' In this regard, he was particularly interested in the relationship between cortical and subcortical structures. He described a cluster of cells (a "ganglion") in the substantia innominata and named it the nucleus of the ansa lenticularis, but it was later renamed the nucleus basalis of Meynert (nbM) by Kölliker in 1896. ${ }^{2}$ Unfortunately, there has been much confusion (in the literature) with regard to terminology. The nbM has been called the nucleus of the ansa lenticularis, the preoptic magnocellular nucleus, the nucleus of the ansa peduncularis, the substantia innominata, the nucleus of the horizontal limb of the diagonal band, and nucleus of the septal plane. ${ }^{3}$ Interest in this nucleus was to remain dormant until the discovery of intracytoplasmic inclusions, called Lewy bodies, in $1913 .{ }^{4}$ These were felt to be pathognomonic for idiopathic Parkinson's disease, and this was a method by which idiopathic Parkinson's disease could be differentiated from post-encephalitic Parkinsonism where Lewy bodies were absent. ${ }^{5}$
Recently there has been a resurgence of interest in the nucleus basalis of Meynert since it was shown to be a major source of cortical cholinergic input. It has been studied extensively in senile dementia of the Alzheimer type (DAT) as well as other illnesses, such as Parkinson's and Huntington's diseases, in which dementia is a component.

This article will review the anatomy, neurochemistry, function and the pathology of the nucleus basalis of Meynert. Its involvement in DAT as well as its possible role as a more general substrate for dementia will be specifically addressed.

\begin{abstract}
Anatomy
In the human brain the nucleus basalis of Meynert is a major component of the substantia innominata. The substantia innominata is situated in the basal forebrain, located in the medial and ventral aspects of the cerebral hemispheres. In addition to the substantia innominata, the basal forebrain contains the septal area, the olfactory tubercle, and parts of the amygdaloid complex. ${ }^{3}$ The nucleus basalis of Meynert is located below the rostral globus pallidus in the substantia innominata.
\end{abstract}

From the Department of Neuropathology. Toronto Western Hospital and University of Toronto Received May 16, 1985. Accepted in revised form November 22, 1985

Reprint requests to: Dr. C. Ezrin-Waters, Neurology Program, Addiction Research Foundation, 33 Russell Street. Toronto. Ontario, Canada M5S 2S1 
In a coronal section it is seen dorsolateral to the optic tract and ventromedial to the anterior commissure. ${ }^{6}$ Rostrally it merges with the nucleus of the diagonal band of Broca. ${ }^{7.8}$ (Figure 1).

There is no clear demarcation between the nbM and other neighbouring cell groups. It is identifiable because the cells are the largest and most hyperchromic in the entire basal forebrain. ${ }^{3}$ However, there is a large cluster of nucleus basalis type neurons along the ventral and lateral edges of the globus pallidus, but many small islands of cell clusters of this type are encountered in other regions of the basal forebrain. ${ }^{6}$ Therefore, drawing precise boundaries for the nucleus basalis is difficult.

The primate nucleus basalis receives afferents from the amygdala, the lateral hypothalamus, the lateral pre-optic area, and the peripeduncular nucleus of the midbrain. The primate peripeduncular nucleus is believed to be analogous to neurons within the brachium of the inferior colliculus in man. ${ }^{9}$

The neurons of the nbM project to the olfactory bulb, the hypothalamus, the amygdala and all parts of the cortex ${ }^{3}$ but the major cortical projections are to prefrontal, frontal and parietal cortices. ${ }^{10}$ The cortical projection arises from cells which react with acetylcholinesterase ${ }^{11.12}$ and choline acetyltransferase $\mathrm{e}^{12}$ indicating that these cells are probably of cholinergic origin. ${ }^{11}$ The cholinergic identity of the nbM neurons was further substantiated by the discovery of immunohistochemical methods for $\mathrm{CAT}^{3.13 .14 .15}$ which specifically label these cells. Therefore, the nbM provides cholinergic input to the cortex and this is currently its most studied connection. The nbM also provides

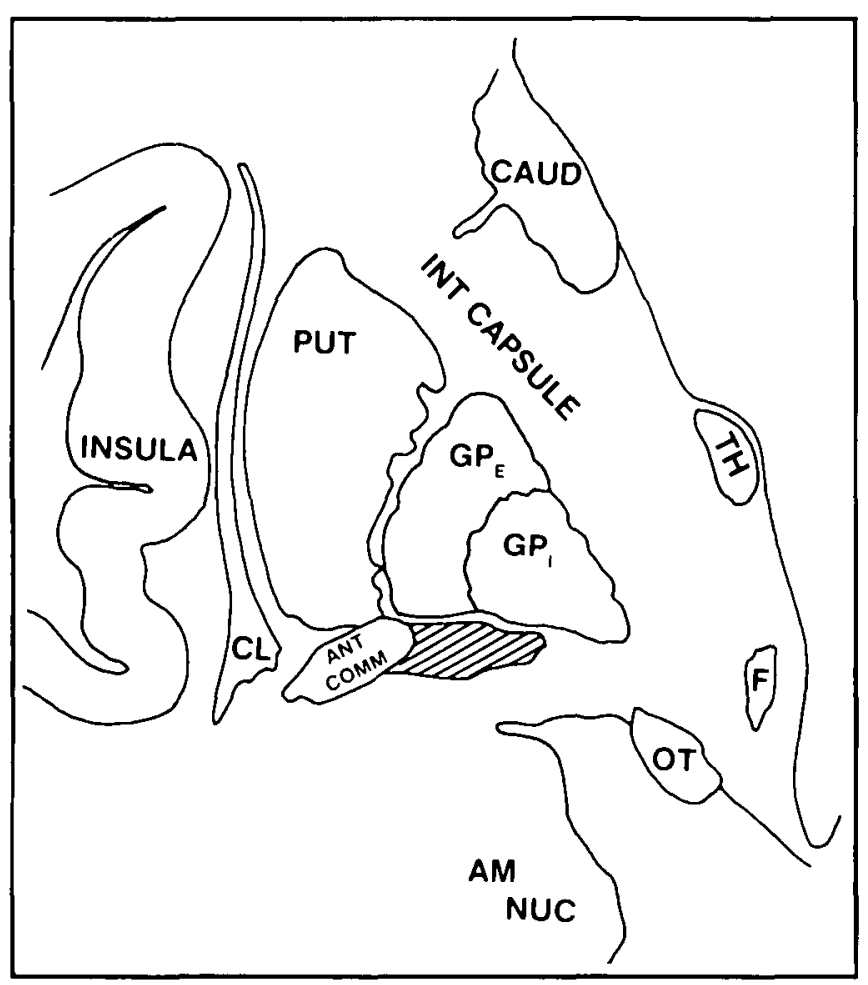

Figure I - Schematic representation of a frontal section through the nbM (cross-hatched). This plane is the one employed for neuronal counts. $C A U D=$ caudate, $T H=$ thalamus, $F=$ fornix, $O T=$ optic tract,$A M$ $N U C=$ amygdaloid nucleus, ANT COMM = anterior commissure, $P U T$ $=$ putamen, $G P E, G P I=$ globus pallidus externa and interna, $C L=$ clausirum. cholinergic input to the amygdala, hippocampus and olfactory bulb, a function it shares with its neighbouring nuclei, the medial septal nucleus and the diagonal band of Broca. ${ }^{3}$

\section{Neurochemistry}

Acetylcholine is synthesized from acetyl CoA and choline by choline acetyltransferase (CAT). It is degraded by acetycholinesterase (AChE), an enzyme present in the synaptic cleft. Hebb et al $^{16}$ showed that undercutting the cerebral cortex caused a reduction in CAT activity in overlying cortex. This indicated that cortical cholinergic input originated from neurons located outside the cortex. ${ }^{10}$

The next step was tracing axons which stained for AChE by histochemical methods from the cortex to their origin. The cell bodies were identified in the basal forebrain. These studies were challenged when other neurotransmitter systems (dopamine, norepinephrine) were found to stain for AChE. Immunocytochemical studies using CAT also yielded conflicting results. ${ }^{10}$

The findings of ablation studies were more consistent. Stereotactic methods for selective lesions were undertaken in rat ventral globus pallidus (VGP) using kainic acid. The rat ventral globus pallidus has been shown to be analogous to the nucleus basalis in primates using comparative neuroanatomic studies. ${ }^{17}$ Kainic acid is an excitotoxin which destroys cell bodies at the injection site leaving traversing axons from distant neurons untouched. ${ }^{10}$ These lesions caused a marked reduction in cholingeric markers in the ipsilateral cerebral cortex. Stereotactic lesions of the thalamus, the internal capsule, the dorsal globus pallidus and the zona incerta did not reduce cortical cholinergic activity. As well, the VGP lesion did not reduce noradrenergic, serotonergic or histaminergic activity." After the VGP lesion, the frontal and parietal cortical regions showed a reduction in CAT activity and AChE staining. ${ }^{10}$ The CAT activity in the frontal and parietal cortices was reduced by up to $70 \%$. There are a small number of cholinergic neurons intrinsic to the corte ${ }^{14}$ which account for the inability to reduce the CAT activity by $100 \%$ with basal forebrain lesions. However, these studies indicate that the major cortical cholinergic innervation comes from the basal forebrain.

The evidence for cortical cholinergic input from the nucleus basalis is impressive. The studies in subhuman species have been consistent, but direct evidence in man was lacking. In 1984, Perry and others demonstrated that the nbM neurons in man were also cholinergic using both histochemical (AChE) technique and biochemical (AChE and CAT) activity. ${ }^{18}$ Therefore, direct evidence for the cholinergic nature of this nucleus in human and subhuman species has been brought forth.

\section{Functional Considerations}

Human subjects receiving scopolamine show impairment of memory and nonmemory cognitive function that is not attributed to altered sensorium alone. ${ }^{19}$ This pattern of dysfunction is similar to that seen with normal aging. ${ }^{19,20}$ It has been postulated that the cognitive disturbances occurring with aging may be secondary to a cholinergic neurotransmitter dysfunction. ${ }^{20}$

Cholinergic enhancers have been used in an attempt to improve memory function in Alzheimer patients. A combination of physostigmine (a centrally active acetylcholinesterase inhibitor) and lecithin (a cholinergic percursor) improved long-term storage and long-term retrieval in three Alzheimer patients studied by Peters and Levin. ${ }^{21}$ Physostigmine alone enhanced long- 
term storage and long-term retrieval in normal male volunteers. ${ }^{22}$ Perry and other ${ }^{23}$ compared mental test scores, cholinergic activity and neuropathological changes in 28 demented patients with appropriate controls (normals). CAT and AChE activity decreased as mean senile plaque count rose, and these changes correlated with the degree of intellectual impairment.

Because of the relationship of the cholinergic system to memory and nonmemory cognitive function, it has been postulated that the nbM may be involved in memory and learning. Lesioning experiments in animals are of paramount importance in defining the role of the nbM in learning. In rats, unilateral basal forebrain lesions reduced ipsilateral cortical cholinergic activity and impaired learning and memory functions. ${ }^{24,25}$ This was measured with avoidance learning behaviour and was felt to reflect acquisition and retention of knowledge. Hepler and others ${ }^{26}$ demonstrated memory impairment in rats with bilateral nbM lesions. This was tested using left/right discrimination on the stem of a T-maze and an alternation discrimination trial on the arms of the T-maze.

There is still a need for clinical pathological correlation with isolated nbM lesions in man. In humans there are other basal forebrain neurons with cholinergic projections, such as the diagonal band of Broca and the medial septum. These neuronal populations may share a role in memory function with the nbM, as they also project to the hippocampus. ${ }^{10}$

\section{Pathology}

New interest in the pathology of the nbM was raised when it was shown that much of the cortical cholinergic innervation was derived from this region. A deficiency of cholinergic activity in senile dementia of the Alzheimer type (DAT), had been recognized for many years. ${ }^{27,28,29}$ Therefore, researchers looked to the nucleus basalis for pathology which would explain the cholinergic loss.

\section{a. Nucleus Basalis and DAT}

Several authors have demonstrated neuronal cell loss ranging from $35-90 \%$ in the nucleus basalis of Alzheimer's patients (Table 1). In addition, in some patients, the nucleoli were significantly reduced in volume; this was positively correlated with percent loss of cells. ${ }^{32}$ Nucleolar volume is thought to represent protein synthetic capacity. ${ }^{37}$ The surviving neurons showed vacuolar abnormalities and neurofibrillary degeneration. ${ }^{7.38}$

The diagnosis of dementia of the Alzheimer type (DAT) was made by clinical history where available and confirmed by the presence of senile plaques, neurofibrillary tangles and granulovacuolar degeneration. Unless otherwise specified, the term "dementia of the Alzheimer type" will be used to refer to both presenile and senile cases with these pathological features. This was differentiated from "senile dementia" in which the above pathology was absent or minimally present (see below).

To assess neuronal loss, most authors examined serial sections of basal forebrain between anterior commissure and optic tract. Cells greater than $\mathbf{3 0}$ microns with visible nucleoli were counted in comparable sections from patients and age-matched controls. In some cases, corrections were made for varying thickness of sections. ${ }^{32}$ Cell loss was estimated by one or two observers and was rated subjectively. The expression of the cell density or loss varied with different authors. Some studies included nucleolar diameter or volume. ${ }^{32,48}$ One group used computer-image analysis of all cells. ${ }^{39}$ The assessment techniques were well controlled, with the counting being done in most cases by persons blind to the diagnosis. The use of age matched controls helped reduce systematic error. Some difficulty arises in comparing different studies. Most authors as noted above counted cells greater than $\mathbf{3 0}$ microns, but in one case cells ranging from $20-30$ microns were counted. ${ }^{30}$ The

Table 1: Nucleus Basalis and DAT

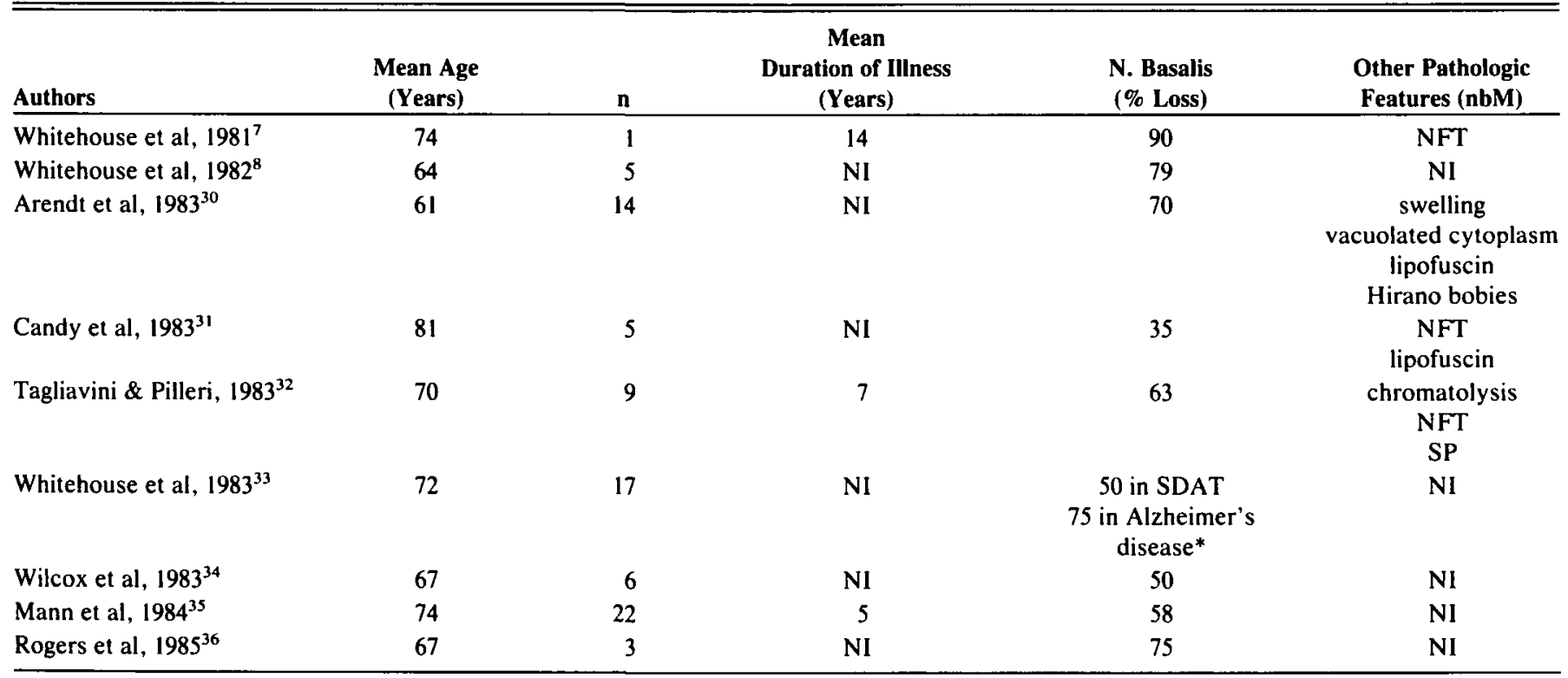

*see text

NFT = neurofibrillary tangles

$\mathrm{SP}=$ senile plaques

$\mathrm{NI}=$ not indicated 
area of the nbM assessed was not identical in all studies; this is partly due to its poor demarcation. Because the neurons were counted in areas of maximum cell density, the identical population was not necessarily studied from case to case.

In spite of the above caveat, a few conclusions can be drawn. The observed neuronal cell loss was greater in the "presenile" (under 65 years) age group. It correlated significantly with both the age of onset and the age of death ${ }^{32}$ (Figure 2). Whitehouse et al attempted to separate senile dementia of the Alzheimer type (greater than 65 years) from Alzheimer's disease (less than 65 years) on the basis of greater neuronal loss in the nbM in the latter. ${ }^{33}$ This may, however, relate to the above observation regarding age of onset of disease. The neuronal cell loss did not correlate with the brain weight or the duration of illness.

In summary, the pathology of the nucleus basalis in DAT consists of neuronal loss, mild chromatolysis of surviving cells, neurofibrillary tangles and occasionally senile plaques. There is no gliosis.

Tagliavini and Pilleri studied the nbM in "simple senile dementia". 32 This is an unfortunate term and applied only by this group. They define simple senile dementia as a mild impairment of cognitive function in the absence of agnosias, apraxias and aphasias. Senile plaques and neurofibrillary tangles are of low density or absent. These patients showed a reduction in nucleolar volume in the nucleus basalis compared with controls, but no significant loss of cells. Both nucleolar volume and cell density were greater than that found in DAT. On the basis of these results, the authors suggest that "simple senile dementia" be separated from DAT.

\section{b. Huntington's Disease}

Huntington's disease (HD) and DAT are both dementing illnesses. However, HD is not associated with a cortical cholinergic abnormality and the CAT level in the HD cortex is normal. ${ }^{40.41}$ As might be expected, there is no loss of neurons from the nbM in HD. ${ }^{32,42}$ A lipovacuolar change similar to that seen in DAT had been described in neurons in HD. ${ }^{43}$ This change, however, is also present in age-matched controls and its significance is unclear. ${ }^{42}$

\section{c. Parkinson's Disease}

Lewy bodies were first identified in the nucleus basalis of Meynert in 1913 in patients with Parkinson's disease. ${ }^{4}$ In addition, neuronal loss, neurofibrillary tangles and gliosis were found. In 1955, it was demonstrated that idiopathic Parkinson's disease and post-encephalitic Parkinson's disease could be differentiated by the presence of Lewy bodies or neurofibrillary tangles respectively. ${ }^{5}$

More recently, the interest in the nbM has been its involvement in the dementia accompanying Parkinson's disease. Researchers have studied the nbM in Parkinson's disease in an attempt to link the dementias of Alzheimer's and Parkinson's diseases.

Table 2 outlines the studies to date on the nbM and Parkinson's disease. Arendt et al studied five cases of idiopathic Parkinson's disease and found significant cell loss in the nbM in four ${ }^{30}$ One case showed significant neuronal loss in the diagonal band of Broca only. Seven post-encephalitic cases were less affected. The remaining neurons showed swelling, disintegration, vacuolization and lipofuscinosis. Whitehouse et al examined the nucleus in 12 patients with Parkinson's disease. ${ }^{44}$ The three patients with post-encephalitic Parkinson's disease did not show loss of neurons in the nucleus basalis. The non-demented idiopathic patients showed a loss of neurons in the mid-portion of the nucleus basalis, of unclear significance. The demented idiopathic Parkinson's disease patients showed significant neuronal cell loss irrespective of the cortical pathology. Neurofibrillary degeneration and senile plaques were present in the cortex and hippocampus in only two of the five patients in this group. The remainder of the pathology of the nucleus basalis was not delineated. Gaspar and Gray reported a 32\% loss of nbM cells in non-demented and a $60 \%$ cell loss in demented patients with idiopathic Parkinson's disease. ${ }^{45}$ Neurofibrillary tangles and senile plaques were more prominent in the latter group but these were not correlated with the degree of cell loss in the nbM. Nakano and Hirano examined eleven patients with confirmed idiopathic Parkinson's disease. ${ }^{46}$ The mental status of the patients was unknown to the authors. The range of cell loss in the nbM was from 0 to approximately $80 \%$. The presence of senile plaques and neurofibrillary tangles in the hippocampus and neocortex did not correlate at all with nbM cell number or density. NbM neurons were lost in some cases without associated DAT.

Tagliavini et al studied six patients with Parkinson's disease and mild to severe cognitive impairment. ${ }^{48}$ In all patients, the neuronal population of the nucleus basalis was reduced, with values ranging from 29.9 to $68.3 \%$ of normal. The nucleolar volumes, however, were unchanged. Cortical Alzheimer type changes were minimal. The neuronal cell loss in the nbM was positively correlated with severity of cognitive change and use of anticholinergics but this was not statistically significant. There was no correlation with the age of the patient and the duration of the illness. The surviving neurons showed lipofuscin, distension and vacuolation of cytoplasm and/or Lewy bodies There was little glial reaction and neurofibrillary tangles were absent.

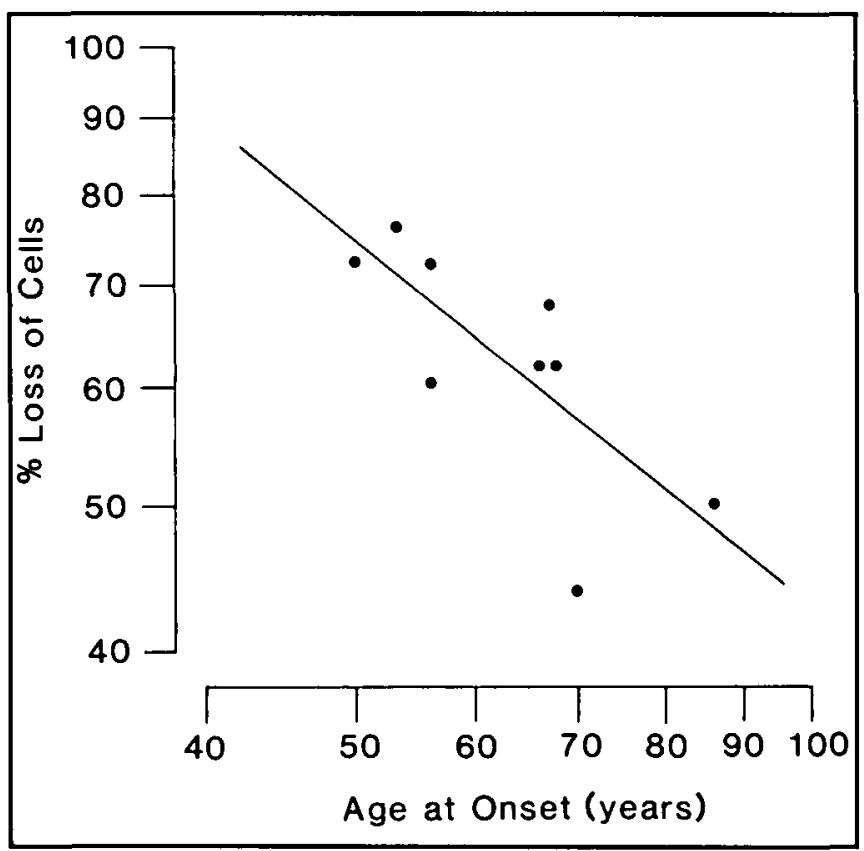

Figure 2 - Alzheimer's disease. Percentage loss of cells in the nbM (log scale) as a function of age at onset (log scale) in 9 patients (Tagliavini and Pilleri, 1983). 


\section{d. Normal Aging}

Because of the similarities between normal aging and early DAT, it is of some interest to assess the nbM in aging. Whitehouse and others ${ }^{49}$ counted the cells in the nbM in 30 cases ( 11 older than 65 years and 19 younger than 65 years). They found no difference between the two groups.

This is not in accordance with the results of McGeer and others $^{50}$ who found an age related change. They used a monoclonal antibody to human CAT in order to specifically identify cholinergic cells in the nbM. With this method, they demonstrated a decline from 400,000 cells in young controls (under 20 years) to 140,000 cells in elderly subjects (greater than 80 years). These were patients without dementia or neurologic disease. In this study, demented patients had even lower cell counts $(45,500$ $100,500)$.

\section{e. Other Dementias}

Tagliavini et al studied five patients with "pure" PSP and one patient with PSP-SDAT. 51 The percent loss of the nucleus basalis in the former group ranged from $12-54 \%$ and the latter patient was $74 \%$. The nucleolar volume was not reduced.

Two patients with Parkinsonism-Dementia Complex of Guam were examined by Nakano \& Hirano. ${ }^{52}$ There was a significant decrease in the number of cells. The cell density was 2.5 cell per frame and the total number of cells was 45.5 compared with 19.5 and 618.1 for controls $(n=14)$. Extensive numbers of senile plaques were seen in the cortices in these two cases.

In a study by Uhl et al, one patient with dementia pugilistica showed a $40 \%$ decrease in the nucleus basalis neurons. ${ }^{53}$ These authors also measured CAT activity in the nbM and several regions of the cortex and found it to be significantly lower than in controls.

Tagliavini and Pilleri examined the nbM in five patients with Pick's disease. ${ }^{32}$ The neurons were not significantly reduced. Uhl et al showed a moderate loss of cells in the nbM in two patients with Pick's disease. ${ }^{54}$ Rogers et al demonstrated neuronal depletion at the anterior level only. ${ }^{36}$ This plane is not identical to the level at which most other authors count cells, which corresponds better with the posterior level of Rogers et al. ${ }^{36}$ Munoz-Garcia and Ludwin examined the nbM in 3 out of 6 of the patients in their report on Pick's disease. 55 They found the population of cells to be reduced to about $30 \%$ compared with controls.

Arendt et al examined the nbM in three patients with Korsakoff's encephalopathy and found that the number of neurons was reduced by $47 \% .{ }^{30}$ The average age of this group was 16 years younger than the control group.

In 1982, Price and others reported a decrease in the nbM neurons in a single case of Down Syndrome. ${ }^{56}$ This has been further elaborated upon in a study by Casanova in which Down Syndrome patients were examined at various ages. ${ }^{57}$ At all ages (16 to 56 years) the Down Syndrome patients had fewer nbM neurons than controls, ranging from approximately $29 \%$ loss to $37 \%$ loss. In six patients with Down Syndrome over 50 years, Mann and others found a $24 \%$ reduction in nbM neurons. ${ }^{35}$ Kirkpatrick and Hicks, however, found no difference in the cell population of the nbM in 6 Down patients (age 1 day to 56 years) compared with controls. ${ }^{58}$

Table 2: Nucleus Basalis and Parkinson's Disease

\begin{tabular}{|c|c|c|c|c|c|}
\hline Authors & Diagnosis & $\mathbf{n}$ & $\begin{array}{c}\text { N. Basalis } \\
\text { (\% Loss) }\end{array}$ & $\begin{array}{l}\text { Other Pathologic } \\
\text { Features (nbM) }\end{array}$ & Cortical Pathology \\
\hline \multirow[t]{2}{*}{ Arendt et al, $1983^{30}$} & IPD & 5 & 70 & $\begin{array}{c}\text { swelling, disintegration } \\
\text { lipofuscin } \\
\text { vacuolated neurons }\end{array}$ & NI \\
\hline & post-encephalitic & 7 & 0 & & \\
\hline Candy et al, $1983^{31}$ & IPD & 3 & moderate & $\begin{array}{l}\text { lipofuscin } \\
\text { no NFT } \\
\text { Lewy bodies }\end{array}$ & no SP, NFT \\
\hline Whitehouse et al, $1983^{44}$ & $\begin{array}{c}\text { IPD (demented) } \\
\text { IPD (non-demented) } \\
\text { post-encephalitic }\end{array}$ & $\begin{array}{l}5 \\
4 \\
3\end{array}$ & $\begin{array}{c}70-80 \\
20 \\
5-10\end{array}$ & NI & SP, NFT $(n=2)$ \\
\hline Gaspar \& Gray, $1984^{45}$ & $\begin{array}{c}\text { IPD (demented) } \\
\text { IPD (non-demented) }\end{array}$ & $\begin{array}{l}18 \\
14\end{array}$ & $\begin{array}{l}60 \\
32\end{array}$ & $\begin{array}{c}\text { Lewy bodies } \\
\text { NFT }\end{array}$ & $\begin{array}{c}\text { SP, NFT } \\
\text { SP, NFT minimal }\end{array}$ \\
\hline Nakano \& Hirano, $1984^{46}$ & IPD & 11 & $0-80$ & Lewy bodies & SP, NFT $(n=3)$ \\
\hline Pendlebury \& Perl, $1984^{47}$ & IPD (non-demented) & 1 & 60 & NI & no SP, NFT \\
\hline Tagliavini et al, $1984^{48}$ & $\begin{array}{l}\text { IPD (demented) } \\
\text { IPD }\end{array}$ & $\begin{array}{l}3 \\
3\end{array}$ & $\begin{array}{l}40-70 \\
30-50\end{array}$ & $\begin{array}{c}\text { lipofuscin } \\
\text { distension } \\
\text { vacuolated neurons } \\
\text { Lewy bodies }\end{array}$ & SP, NFT minimal \\
\hline Rogers, $1985^{36}$ & $\begin{array}{c}\text { IPD (demented) } \\
\text { IPD (non-demented) }\end{array}$ & $\begin{array}{l}3 \\
1\end{array}$ & $\begin{array}{l}75 \\
40\end{array}$ & $\begin{array}{c}\text { NFI } \\
\text { Lewy bodies }\end{array}$ & $\mathrm{Nl}$ \\
\hline
\end{tabular}

IPD = Idiopathic Parkinson's Disease

NFT = neurofibrillary tangles

$\mathrm{SP}=$ senile plaques

$\mathrm{NI}=$ not indicated 
One patient with dementia and cortico-striato-spinal degeneration showed no cell loss in the nbM. ${ }^{59}$ In the three patients with dementia and motor neuron disease examined by Horoupian and others, there was similarly no cell loss from the nbM. ${ }^{60}$

A 42 year old man with Creutzfeldt-Jakob disease had $45 \%$ neuronal loss in the nbM. ${ }^{61}$ Of note, these authors had previously examined the nbM in chronic alcoholism without dementia $(n=5)$, schizophrenia $(n=3)$ and infantile brain damage $(n=12$, mean age 22 years) and found no decrease in neuronal counts and maximum population density. ${ }^{30}$

Recently, Rogers et al assessed neuronal population and density of the nbM using a complex statistical method..$^{36}$ They examined many of the diseases listed above with similar findings. DAT and idiopathic Parkinson's disease were associated with a striking cell loss, while Creutzfeldt-Jakob and PSP showed a lesser loss. In addition, they looked at amyotrophic lateral sclerosis and multiple sclerosis and found no cell loss. Individual cases of cerebral AVM, cortical atrophy, cervical spondylosis with myelopathy, Down's syndrome, Hallervorden-Spatz disease, Huntington's disease, Pick's disease, striatonigral degeneration and SSPE showed variable results.

\section{Conclusion}

The nucleus basalis of Meynert is an important source of cortical cholinergic innervation. Evidence for severe neuronal loss in this nucleus in DAT has been reviewed. As well, moderate to severe loss of cells is seen in Parkinson's disease, progressive supranuclear palsy-SDAT and dementia pugilistica. Huntington's disease spares this nucleus. ${ }^{42}$

It has been proposed that the loss of cholinergic activity seen in DAT is caused by a loss of cholinergic cells in the nucleus basalis. In monkeys, it has been shown that neuritic plaques are rich in acetylcholinesterase, suggesting that the neurites composing the plaques are extensions of cholinergic cells. ${ }^{62}$ It is therefore postulated that plaques represent in part degenerating neurites of nucleus basalis neurons.

Is the nbM neuronal degeneration related to pathological processes underlying DAT? Most of the cases noted above, in which there was severe and significant cell loss in the nbM, also showed the typical neuropathological changes of DAT (neurofibrillary degeneration and senile plaques). This includes all of the DAT cases, 2 of the 5 cases of Parkinson's disease, ${ }^{44} 18$ of the cases of IPD in Gaspar and Gray's study ${ }^{45} 1$ case of progressive supranuclear palsy - DAT, ${ }^{51}$ and the Down Syndrome patients over 50 years of age. ${ }^{35}$ Nakano and Hirano, however, have shown that neurons can be lost in Parkinson's disease without concomitant DAT. ${ }^{46}$ As well, Pendelbury and Perl found $60 \%$ cell loss in the $n b M(n=1)$ compared with an age-matched control in the absence of dementia, senile plaques and neurofibrillary tangles. ${ }^{47}$ Gaspar and Gray studied 14 patients whose mental statuses were known..$^{45}$ These 14 non-demented patients showed a 30 percent loss of cells in the nbM. Cortical presence of neurofibrillary tangles and senile plaques was minimal or absent. Therefore, senile plaques are not necessarily associated with degenerating nbM neurons. That the nbM is involved in DAT appears correct, but it is likely only one component in a multifactorial problem. That the $\mathrm{nbM}$ is a major source of cortical cholinergic input has been well established. The role that the nbM and the cholinergic system plays is probably similar in a wide variety of dementing illness. Elucidation of this role will depend upon further work integrating clinical and pathological studies.

\section{ACKNOWLEDGEMENT}

The authors would like to thank Dr. M. Freedman and Dr. A.E. Lang for their helpful advice, and Nancy Campbell, Evelyn Millar and Yvonne Bedford for their secretarial assistance.

\section{REFERENCES}

1. Whitehouse PJ. Theodor Meynert: Foreshadowing modern concepts of neuropsychiatric pathophysiology. Neurology 1985; 35 : 389-393.

2. Kölliker A. Handbuch der Gewebelehre des Menschen. Vol 2 -Nervensystem 1896; Leipzig: Engelmann.

3. Mesulam MM, Mufson EJ, Levey ALet al. Cholinergic innvervation of cortex by the basal forebrain: cytochemistry and cortical connections of the septal area, diagonal band nuclei, nucleus basalis (substantia innominata) and hypothalamus in the rhesus monkey. J Comp Neurol 1983; 214: 170-197.

4. Lewy FH. Zur pathologischen Anatomie der Paralysis Agitans. Disch Z Nervenheilkd 1913; 50: 50-55.

5. Von Buttlar-Brentano K. Das Parkinsinsyndrom im Lichte der lebensgeshichtlichen Veranderungen des Nucleus Basalis. J Hirnforsch 1955; 2: 55-76.

6. Hedreen JC, Struble RG, Whitehouse PJ et al. Topography of the magnocellular basal forebrain system in human brain. J Neuropath Exp Neurol 1984; 43: 1-21.

7. Whitehouse PJ, Price DL, Clark AW et al. Alzheimer Disease: evidence for selective loss of cholinergic neurons in the nucleus basalis. Ann Neurol 1981; 10: 122-126.

8. Whitehouse PJ, Price DL, Struble RG et al. Alzheimer's Disease and senile dementia: loss of neurons in the basal forebrain. Science 1982; 215: 1237-1239.

9. Jones EG, Burton H, Saper CB et al. Midbrain diencephalic and cortical relationships of the nucleus basalis of Meynert and associated structrures in primates. J Comp Neurol 1976; 167: 385-397.

10. Coyle JT, Price DL, DeLong MR. Alzheimer's Disease: a disorder of cortical cholinergic innervation. Science 1983:219: 1184-1190.

11. Johnston MV, McKinney M, Coyle J. Evidence for a cholinergic projection to neocortex from neurons in basal forebrain. Proc Natl Acad Sci USA 1979; 76: 5392-5396.

12. Lehmann J, Nagy JI, Atmadja $S$ et al. The nucleus basalis magnocellularis: the origin of a cholinergic projection to the neocortex of the rat. Neuroscience 1980; 5: 1161-1174.

13. McGeer PL, McGeer EG, Singh VK et al. Choline acetyltransferase localization in the central nervous system by immunohistochemistry. Brain Res 1974; 81: 373-379.

14. Hattori T, Singh VK, McGeer EG et al. Immunohistochemical localization of choline acetyltransferase containing neostriatal neurons and their relationship with dopaminergic synapses. Brain Res 1976; 102: 164-173.

15. Kimura H, McGeer PL, Peng JH et al. The central cholinergic system studied by choline acetyltransferase immunohistochemistry in the cat. J Comp Neurol 1981; 200: 151-201.

16. Hebb CO, Krnjevic K, Silver A. Effect of undercutting on the acetylcholinestrase and choline acetyltransferase activity in the cat's cerebral cortex. Nature 1963; 198: 692.

17. Parent A, Gravel S, Olivier A. The extrapyramidal and limbic systems relationship at the globus pallidus level: a comparative histochemical study in the rat, cat, and monkey. Adv Neurol $1979 ; 24: 1-24$.

18. Perry RH, Candy JM, Perry EK et al. The substantia innominata and adjacent regions in the human brain: histochemical and biochemical observations. J Anat 1984; 138(4): 713-732.

19. Drachman DA. Memory and cognitive function in man: does the cholinergic system have a specific role? Neurology 1977; 27: 783-790. 
20. Drachman DA, Leavitt J. Human memory and the cholinergic system. A relationship to aging? Arch Neurol 1974; 30: 113-121.

21. Peters BH, Levin HS. Effects of physostigmine and lecithin on memory in Alzheimer Disease. Ann Neurol 1979; 6: 219-221.

22. Davis KL, Mohs RC, Tinklenberg JR et al. Physostigmine: improvement of long-term memory processes in normal humans. Science 1978; 201: 272-274.

23. Perry EK, Tomlinson BE, Blessed $\mathrm{G}$ et al. Correlation of cholinergic abnormalities with senile plaques and mental test scores in senile dementia. Brit Med J 1978; 2: 1457-1459.

24. Lo Conte G, Bartolini K, Casamenti F et al. Lesions of cholinergic forebrain nuclei: changes in avoidance behaviour and scopolamine actions. Pharmacol Biochem Behav 1982; 17: 933-937.

25. Flicker C, Dean RL, Watkins DL et al. Behavioural and neurochemical effects following neurotoxic lesions of a major cholinergic input to the cerebral cortex in the rat. Pharmacol Biochem Behav 1983; 18: 973-981.

26. Hepler DJ, Olton DS, Wenk GL et al. Lesions in nucleus basalis magnocellularis and medial septal area of rats produce qualitatively similar memory impairments. J Neurosci 1985; 5: 866-873.

27. Davies P, Maloney AJR. Selective loss of central cholinergic neurons in Alzheimer's Disease. Lancet 1976; 2: 1403.

28. Perry EK, Perry RH, Blessed G et al. Necropsy evidence of central cholinergic deficits in senile dementia. Lancet 1977; 1: 189.

29. White P, Goodhardt MJ, Keet JP, et al. Neocortical cholinergic neurons in elderly people. Lancet 1977; 1: 668-671.

30. Arendt T, Bigl V, Arendt A, et al. Loss of neurons in the nucleus basalis of Meynert in Alzheimer's Disease, Paralysis Agitans and Korsakoff's Disease. Acta Neuropathologica 1983;61: 101-108.

31. Candy JM, Perry RH, Perry EK et al. Pathological changes in the nucleus of Meynert in Alzheimer's and Parkinson's Disease. J Neurol Sci 1983; 54 (59): 277-289.

32. Tagliavini F, Pilleri G. Basal Nucleus of Meynert. A neuropathological study in Alzheimer's Disease, simple senile dementia, Pick's Disease and Huntington's Chorea. J Neurol Sci 1983; 62: 243-260.

33. Whitehouse PJ, Hedreen JC, White III CL, et al. Neuronal loss in the basal forebrain cholinergic system is more marked in Alzheimer's Disease than in senile dementia of the Alzheimer type. (Abstract) Ann Neurol 1983; 10: 149.

34. Wilcox GR, Esiri MM, Bowen DM et al. The Nucleus Basalis in Alzheimer's Disease. Cell counts and cortical biochemistry. Neuropath Appl Neurobiol 1983;9: 175-179.

35. Mann DMA, Yates PO, Marcyniuk B. Alzheimer's presenile dementia, senile dementia of the Alzheimer type and Down's Sydrome in middle age form an age related continuum of pathological changes. Neuropath Appl Neurobiol 1984; 10: 185-207.

36. Rogers JD, Brogan D, Mirra SS. The nucleus basalis of Meynert in neurological disease. A quantitative morphological study. Ann Neurol 1985; 17: 163-171.

37. Mann DMA. Nerve cell protein metabolism and degenerative disease. Neuropath Appl Neurobiol 1982; 8: 161-176.

38. Whitehouse PJ, Struble RG, Clark AW et al. Alzheimer Disease: plaques, tangles and the basal forebrain. (Letter) Ann Neurol 1982; 12: 494.

39. Whitehouse PJ, Hedreen JC, Jones BE et al. A computer analysis of neuronal size in the nucleus basalis of Meynert in patients with Alzheimer's Disease. (Abstract) Ann Neurol 1983; 10: 149.

40. Lloyd KG, Mohler H, Heitz P, et al. Distribution of choline acetyltransferase and glutamate decarboxylase within the substantia nigra and in other brain regions from control and Parkinson's Disease. J Neurochem 1975; 25: 789-795.
41. McGeer PL, McGeer EG. Enzymes associated with the metabolism of catecholamines, acetycholine and GABA in human controls and patients with Parkinson's Disease and Huntington's Chorea. J Neurochem 1976; 26: 65-76.

42. Clark AW, Parhad IM, Folstein SE et al. The nucleus basalis in Huntington's Disease. Neurology 1983; 33: 1262-1267.

43. Averback $P$. Lesions of the nucleus ansae peduncularis in neuropsychiatric disease. Arch Neurol 1981; 230-235.

44. Whitehouse PJ, Hedreen JC, White CL III et al. Basal forebrain neurons in the dementia of Parkinson's Disease. Ann Neurol 1983; 13: 243-248.

45. Gaspar P, Gray F. Dementia in idiopathic Parkinson's Disease. Acta Neuropathol (Berl) 1984; 64: 43-52.

46. Nakano I, Hirano A. Parkinson's Disease: neuron loss in the nucleus basalis without concomitant Alzheimer's Disease. Ann Neurol 1984; 15: 415-418.

47. Pendlebury WW, Perl DP. Nucleus basalis of Meynert: severe cell loss in Parkinson's Disease without dementia. (Abstract) Ann Neurol 1984: 16: 129.

48. Tagliavini F, Pilleri G, Bouras Cet al. The basal nucleus of Meynert in idiopathic Parkinson's Disease. Acta Neurol Scand 1984; 69: 20-28.

49. Whitehouse PJ, Parhard IM, Hedreen JC et al. Integrity of the nucleus basalis of Meynert in normal aging. (Abstract) Neurology (Suppl 2) 1983; 33: 159.

50. McGeer PL, McGeer EG, Suzuki J et al. Aging, Alzheimer's Disease, and the cholinergic system of the basal forebrain. Neurology $1984 ; 34: 741-745$.

51. Tagliavini F, Pilleri G, Bouras $C$ et al. The basal nucleus of Meynert in patients with progressive supranuclear palsy. Neurosci Lett $1984 ; 44: 37-42$.

52. Nakano I, Hirano A. Neuron loss in the nucleus basalis of Meynert in Parkinsonism-Dementia complex of Guam. Ann Neurol 1983; 13: 87-91.

53. Uhl GR, McKinney M, Hedreen JC et al. Dementia Pugilistica: loss of basal forebrain cholinergic neurons and cortical cholinergic markers. (Abstract) Ann Neurol 1982; 12: 99.

54. Uhl GR, Hilt DC, Hedreen JC. Pick's Disease (lobar sclerosis): depletion of neurons in the nucleus basalis of Meynert. Neurology 1983; 33: 1470-1473.

55. Munoz-Garcia D, Ludwin SR. Classic and generalized variants of Pick's Disease. A clinicopathological, ultrastructural, and immunocytochemical Comparative Study. Ann Neurol 1984; 16: 467-480.

56. Price DL, Whitehouse PJ, Struble RG et al. Alzheimer's Disease and Down's Syndrome. Ann NY Acad Sci 1982; 396: 145-164.

57. Casanova MF, Walker LC, Whitehouse PJ et al. Abnormalities of the nucleus basalis in Down's Syndrome. Ann Neurol 1985; 18: 310-313.

58. Kirkpatrick JB, Hicks P. Nucleus basalis in Down's Syndrome. J Neuropath Exp Neurol 1984; 43: 307.

59. Clark AW, Lehmann J, Whitehouse PJ. Cortico-striato-spinal degeneration (CSSD) mimicking Alzheimer's Disease: Studies of the nucleus basalis of Meynert and cortical choline acetyltransferase. (Abstract) J Neuropath Exp Neurol 1983; 42: 334.

60. Horoupian DS, Thal L, Katzman R et al. Dementia and motor neuron disease: morphometric, biochemical, and golgi studies. Ann Neurol 1984; 16: 305-313.

61. Arendt T, Bigl V, Arendt A. Neurone loss in the nucleus basalis in Meynert in Creutzfeldt-Jakob Disease. Acta Neuropath 1984; 65(1): 85-88.

62. Struble RG, Cork LC, Whitehouse PJ, et al. Cholinergic innervation in neuritic plaques. Science 1982; 216: 413-414. 